\title{
Microwave Nondestructive Evaluation of Thermal Barrier Coated Turbine Blades Using Correlation Analysis
}

DOI:

10.1109/EuMC.2016.7824394

\section{Document Version}

Accepted author manuscript

Link to publication record in Manchester Research Explorer

\section{Citation for published version (APA):}

Akbar Jalaludin Khan, M. F., Wielgat, M., \& Knowles, J. F. (2016). Microwave Nondestructive Evaluation of Thermal Barrier Coated Turbine Blades Using Correlation Analysis. In European Microwave Week 2016 https://doi.org/10.1109/EuMC.2016.7824394

\section{Published in:}

European Microwave Week 2016

\section{Citing this paper}

Please note that where the full-text provided on Manchester Research Explorer is the Author Accepted Manuscript or Proof version this may differ from the final Published version. If citing, it is advised that you check and use the publisher's definitive version.

\section{General rights}

Copyright and moral rights for the publications made accessible in the Research Explorer are retained by the authors and/or other copyright owners and it is a condition of accessing publications that users recognise and abide by the legal requirements associated with these rights.

\section{Takedown policy}

If you believe that this document breaches copyright please refer to the University of Manchester's Takedown Procedures [http://man.ac.uk/04Y6Bo] or contact uml.scholarlycommunications@manchester.ac.uk providing relevant details, so we can investigate your claim.

\section{OPEN ACCESS}




\section{Microwave Nondestructive Evaluation of Thermal Barrier Coated Turbine Blades Using Correlation Analysis}

\author{
Muhammad Firdaus AJK, \\ Robin Sloan, Christopher I Duff \\ School of Electrical and Electronic \\ Engineering University of Manchester \\ M13 9PL United Kingdom
}

\author{
Marcin Wielgat \\ Alstom TRIM \\ Baden, Switzerland
}

\author{
James F Knowles \\ JK NDE Consultancy Ltd \\ United Kingdom
}

\begin{abstract}
The ability of microwave energy to propagate through a dielectric material and interact at boundaries makes microwave imaging techniques attractive for inspection of defects under dielectric layers. In this paper, microwave non-destructive testing/evaluation (NDT/E) using Ka-band open ended rectangular waveguide (OERW) energy launch, in conjunction with broad frequency swept signal processing is used to inspect the thermal barrier coated turbine blades sample. A correlation technique utilizing both the magnitude and phase information of the reflection coefficient at the waveguide aperture is used. Representative turbine blade with defects on the metal, visibly hidden by the Thermal Barrier Coating (TBC) is measured and the technique verified.
\end{abstract}

Keywords-Thermal barrier coating, turbine blade, open-ended waveguide, microwave NDT/E.

\section{INTRODUCTION}

Inspection of turbine blades is one of the critical evaluations in the turbine system due to its catastrophic failure consequences to the whole system. Inconel turbine blades are usually coated with Zirconia based thermal barrier coatings (TBC) to protect against high temperature and high pressure gases. A crack on the metal blade which normally begins from the surface due to corrosion and stress has to be inspected nondestructively. The formation of a crack on a single turbine blade can lead to catastrophic failure, in which part of a defected blade breaks away from the spinning rotor and severely damages other blades. Therefore, the ability to detect and locate the defect is crucial for maintenance cost reduction and ensuring system safety and reliability, with minimal downtime.

There are several established NDT/E methods available including eddy-current, magnetic-particle, ultrasonic, X-ray, acoustic emission, thermography and liquid penetrant inspection [1]. Although each of these methods has their advantages on their own application, there are certain disadvantages in inspecting the TBC coated turbine blade. For instance, ultrasonic methods are not capable of penetrating highly porous materials due to the attenuation and require a couplant in to transmit the signal into the sample under test. Eddy current methods are extensively used in industry for surface crack and corrosion detection but this method does not work well when inspecting lossless dielectric materials due to field penetration limitations and their insulator properties. Magnetic-particle inspection is limited to be used in electrically conducting materials such that the surface must be accessible and in contact with the probe. Microwave NDT/E technique is the answer for real time in-situ, non-contact and one-sided measurements, without the need for an intermediate matching material to transmit the signal into the sample under test which able to complement established techniques.

Transmission and reflection of microwave energy at the boundaries of dielectric coating layers and metal respectively can reveal crucial information regarding the metal surface, as is the case for a turbine blade coated with TBC. As a result, a significant amount of research and development has taken place using various open-ended microwave probes for various types of examination, such as delamination evaluation in layered-dielectric slabs [2], [3] and thickness variation in stratified composites [4], [5]. However, those presented methods are mainly based on a spot frequency measurement and some of them require the probes to be in contact with the sample. Practically, the standoff distance between the surface under test and the detection probe is desirable to facilitate the probe to scan through any lifted surface without damaging the sample. The selected spot frequency varies for different type of coating material, coating thickness and the different stand-off distance itself. Some of the analyses presented consider only the magnitude response while others have considered the phase response. It is not always ideal to inspect different properties of coating at single frequency and single analysis (magnitude or phase) since the optimum frequency varies accordingly. Thus, this paper presents the capability of wideband microwave $\mathrm{NDT} / \mathrm{E}$ techniques using correlation technique (using both magnitude and phase response) to inspect representative TBC coated turbine blade samples. Simulation and measurement of sample with machined defects are used to test this proposed technique.

\section{THEORETICAL APPROACH}

Microwave NDT/E can generally utilize the magnitude and phase information of reflected and/or transmitted energy in terms of the reflection and/or transmission coefficients, to reveal abnormalities, or changes in characteristics, inside or at the boundary of the material(s) under inspection. Bakhtiari et al. [6] have presented a near field theoretical model governing 
the complex reflection coefficient as a wave propagates through multiple layers with differing dielectric properties. Figure 1 illustrates a schematic representation of a flat turbine blade material sample, including a defect area introduced between the TBC and metal. As the microwave energy is transmitted from the open ended rectangular waveguide (OERW) towards the front TBC boundary, a proportion of this incident wave will be reflected from the interface and the rest transmitted and propagated through the TBC layer. The standoff distance, occupied by air, is defined as the distance between the waveguide aperture and the sample surface. A defect is represented here by an air pocket hole on the metal surface, underneath the TBC to represent a crack or hole.

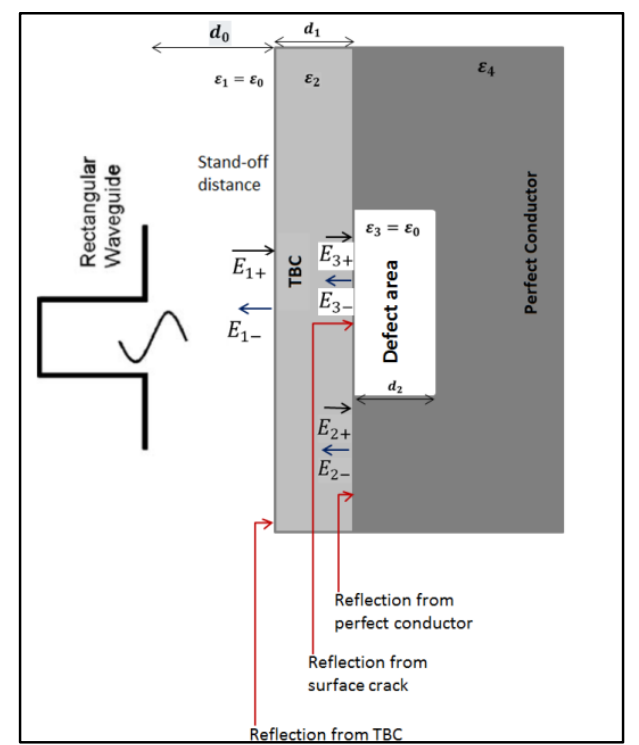

Fig. 1. Schematic representation of reflection and transmission of EM wave incident upon flat turbine blade material sample (the arrows indicate the direction of propagation of the incident and reflected wave components)

A description of the forward and backward traveling waves in each layer of the defect area can be formulated by enforcing the appropriate boundary conditions at each interface: air-TBC; TBC-air (defect area); and air (defect area)-conductor boundaries. The width and height dimensions of the waveguide are given by $a$ and $b$ as shown in Figure 2. For $\mathrm{TE}_{10}$ mode, the excitation aperture field distribution is given by [7]:

$$
E_{y}(x, y, 0)=\left\{\begin{array}{l}
\sqrt{2 / a b} \cos \frac{\pi x}{a} \text { Over aperture } \\
0 \quad \text { Elsewhere }
\end{array}\right.
$$

The complex reflection coefficient, $\boldsymbol{\Gamma}$ can be derived in terms of complex admittance, $\mathrm{Y}$ :

$$
\Gamma=\frac{Y-1}{Y+1}
$$

where

$$
\begin{aligned}
Y= & \frac{j 2}{(2 \pi)^{2} \sqrt{1-\left(\frac{\pi}{2 a}\right)^{2}}} \int_{R=0}^{\infty} \int_{\theta=0}^{2 \pi} F\left\{\left(K^{2}-R^{2} \cos ^{2} \theta\right)(2 C+\right. \\
& \left.\left.\frac{j F}{X_{Z}}\right)\right\} R d \theta d R
\end{aligned}
$$

$$
F=\frac{4 \pi \sin \left(\frac{X_{y} B}{2}\right) \cos \left(\frac{X_{x} A}{2}\right)}{X_{y}\left[\pi^{2}-\left(X_{x} A\right)^{2}\right]} \sqrt{\frac{2 A}{B}}
$$

and

$$
C=-\frac{F e^{j X_{Z} D}}{2 X_{Z} \sin \left(X_{Z} D\right)}
$$

and

$$
\begin{aligned}
& A=k_{0} a, B=k_{0} b, D_{\text {non-defect }}=k_{0}\left(d_{0}+d_{1}\right) \\
& D_{\text {defect }}=k_{0}\left(d_{0}+d_{1}+d_{2}\right)
\end{aligned}
$$

where $\mathrm{R}$ and $\theta$ are the variables of integration in polar coordinates.

\section{IMAGING TECHNIQUE AND EXPERIMENTAL SETUP}

A flat, representative sample of the turbine blade material stack is used in this study to evaluate the capabilities of nearfield microwave NDT/E techniques using OERW operating over Ka-band (26.5 to $40 \mathrm{GHz}$ ) frequency range to detect visibly hidden defects underneath the TBC. The turbine blade model structure for both measurements and simulations consists of flat, conductive Inconel coated with the dielectric TBC. Phase and magnitude variations of the reflected coefficient $\boldsymbol{\Gamma}$ over a wide frequency range can be demonstrated as a result of introduced defects, from which an image of a defect area can be generated. In this paper, the correlation between two reflection coefficient vectors consist of both magnitude and phase information is proposed to evaluate the capability and resolution of this technique for defect characterization of turbine blade. Using a mathematical correlation coefficient, $\delta_{\text {refN }}$ between the data at the measurement location $\left(\mathrm{v}_{\mathrm{N}}\right)$ and that at a non-defect location $\left(\mathrm{v}_{\mathrm{ref}}\right)$ allows use of both the magnitude and phase information at each image point [8]. The correlation coefficient $\delta_{\text {refN }}$ can be defined as:

$$
\delta_{\text {refN }}=\frac{\left|v_{N}^{H} v_{r e f}\right|}{\left\|v_{N}|| \mid v_{r e f}\right\|}
$$

where $|\cdot|$ and $\|\cdot\|$ are the modulus of a complex scalar and the Euclidean norm of a complex vector, respectively. A low correlation between two vectors will indicate abnormalities location.

\section{3D ELECTROMAGNETIC MODELLING}

The 3D electromagnetic model is developed using commercial software CST. Ka-band OERW (with standard radiating aperture dimensions of $7.11 \times 3.56 \mathrm{~mm}$ ) as shown in Figure $2 \mathrm{a}$ is used in the simulation over a frequency range of 26.5 to $40 \mathrm{GHz}$. The blade sample is modelled as TBC backed by a perfect electrical conductor (PEC) representing the bonding layer between the TBC and Inconel and the Inconel underneath. The TBC is modelled as a lossless dielectric with relative permittivity of 25 [9]. A hole of $1 \mathrm{~mm}$ deep protruding down from the Inconel surface underneath the TBC coating, as shown in Figure 2b, with a diameter of $1.6 \mathrm{~mm}$, is simulated at stand-off distances of $2 \mathrm{~mm}$. The simulation setup parameters, waveguide and sample dimensions are provided in Table 1.

where 


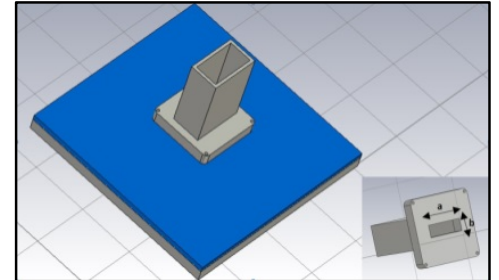

(a)

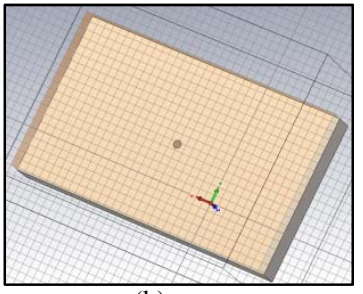

(b)
Fig. 2. (a) The K band OERW and the sample (grey metal with blue TBC coating). Aperture from the flange side is shown in inset. (b) Round hole of diameter $1.6 \mathrm{~mm}$ is introduced on Inconel surface underneath TBC coating

Table I. Simulation Setup Parameters, WAVEguide AND SAmple DIMENSIONS

\begin{tabular}{|l|l|}
\hline \multicolumn{1}{|c|}{ Parameter } & \multicolumn{1}{c|}{ Value } \\
\hline Waveguide dimension (a x b) & $7.11 \mathrm{~mm} \times 3.56 \mathrm{~mm}$ \\
\hline Sample size & $50 \mathrm{~mm} \times 40 \mathrm{~mm}$ \\
\hline Thickness of TBC & $0.7 \mathrm{~mm}$ \\
\hline Thickness of Inconel & $4 \mathrm{~mm}$ \\
\hline Sampling frequency range & $26.5-40 \mathrm{GHz}$ \\
\hline Number of frequency points & 101 \\
\hline Scanning step size & $2 \mathrm{~mm}$ \\
\hline
\end{tabular}

Figure 3 shows the simulated results obtained using the correlation techniques described in section III.

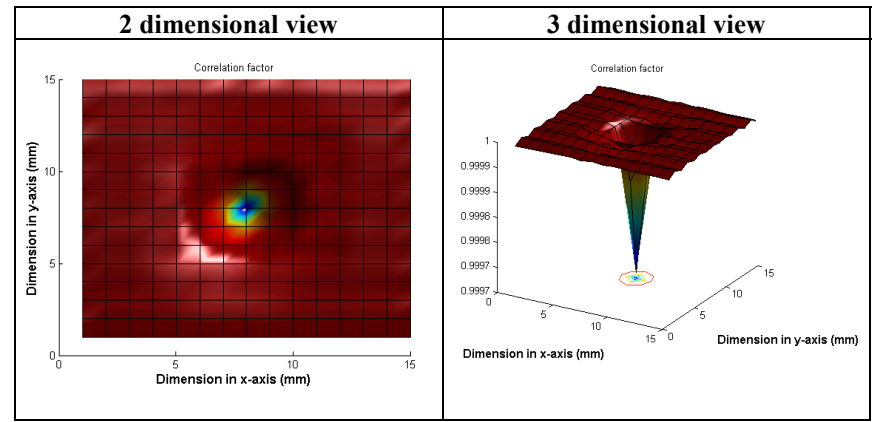

Fig. 3. Simulated scanning image of $1.6 \mathrm{~mm}$ diameter hole on Inconel with stand-off distance of $2 \mathrm{~mm}$

The visibly hidden hole beneath the TBC is clearly identified in the images. The correlation value shows almost equal to 1 for complex reflection coefficient at non defect area, and value of less than 1 for area comprising of a defect. Although this technique requires known information about a defect-free sample as a reference, it is desirable to distinguish different types of defect such as crack on metal or delamination.

\section{Microwave Ndt/E MeAsurements}

The blade material representative sample defect is flat bottom back drilled through the Inconel, as shown in Figure 4, such that the $1.6 \mathrm{~mm}$ diameter hole with a depth of $4 \mathrm{~mm}$ will extend through the metal and bonding coat up to and below the TBC, whilst leaving its surface undisturbed, flat and smooth. This sample is placed on a metal during scanning such that it replicates the schematic representation as shown in Figure 1. The dimensions of the sample are provided in Table 2.

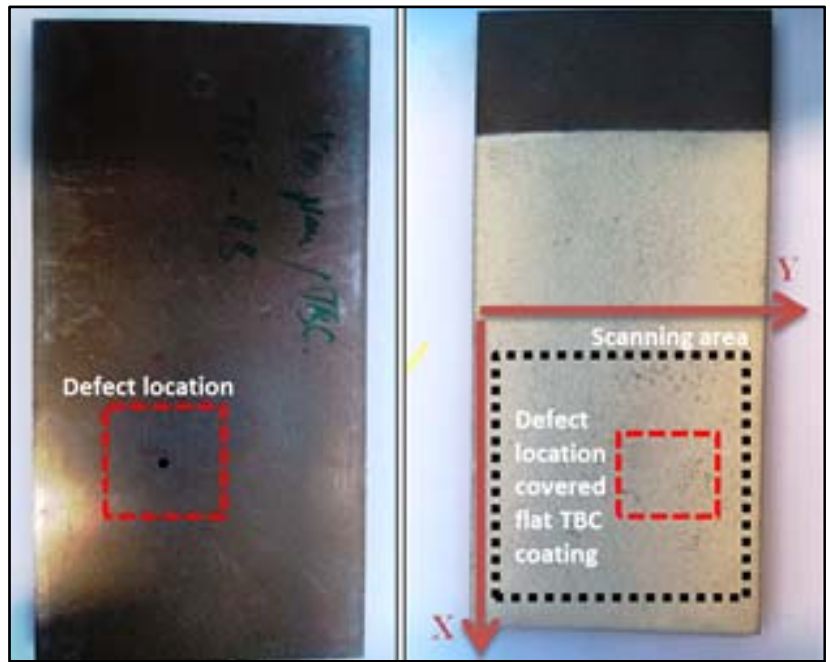

Fig. 4. Details of the turbine blade material sample under test

TABle II. TuRbine Blade SAmple Dimensions

\begin{tabular}{|l|l|}
\hline \multicolumn{1}{|c|}{ Parameter } & \multicolumn{1}{c|}{ Value } \\
\hline Sample size & $100 \mathrm{~mm} \times 50 \mathrm{~mm}$ \\
\hline Inconel metal thickness & $4 \mathrm{~mm}$ \\
\hline TBC thickness & $0.7 \mathrm{~mm}$ \\
\hline Hole diameter & $1.6 \mathrm{~mm}$ \\
\hline
\end{tabular}

The experimental setup for turbine blade sample inspection is shown in Figure 5. The Ka-band OERW probe is mounted on the robotic positioner and scanned over the blade surface in the labelled XY plane with a step size of $2 \mathrm{~mm}$. Two stand-off distances is measured; $1 \mathrm{~mm}$ and $2 \mathrm{~mm}$ is used in this measurement. The calibrated, battery powered portable VNA is used to measure $S_{11}$ from 26.5 to $40 \mathrm{GHz}$, as a linear sweep with 101 frequency points. A laptop is used to automate the robotic platform scanning, data capture and to perform the signal processing for image generation of the inspected area, using the correlation technique.

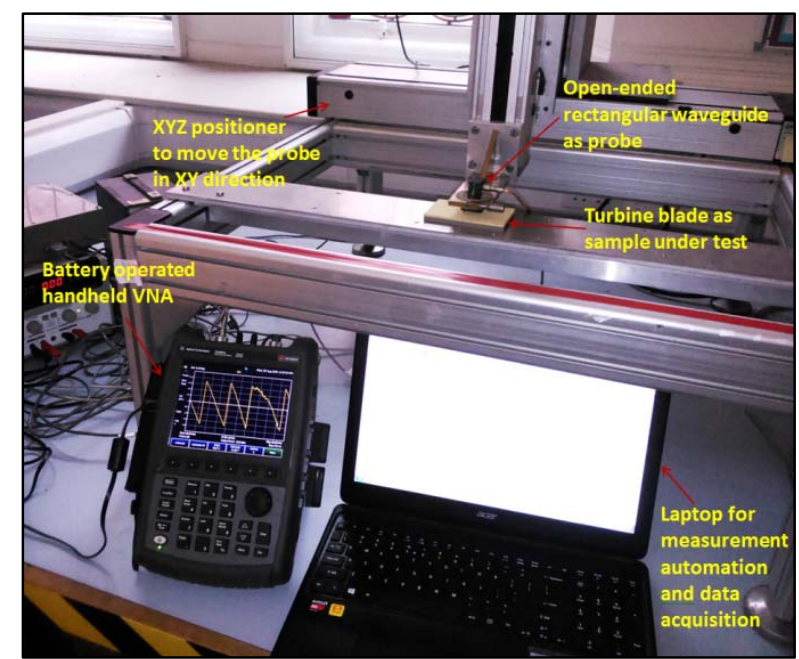

Fig. 5. Experimental setup for microwave NDE of turbine blade sample 
Figure 6 and 7 show the C-scan raster scanning results of the sample under test using the correlation technique, at standoff distances of $1 \mathrm{~mm}$ and $2 \mathrm{~mm}$ respectively. It is observed that the correlation technique can image the defect at varying standoff distances without the knowledge of optimum frequency of operation. The measurement result shows inconsistent correlation values over non-defect area. This is because the phase ripples observed over the non-defect due to the discontinuity effect from the edge of the sample. The simulation and measurement results generally agree well and successfully detect this defect using proposed technique.

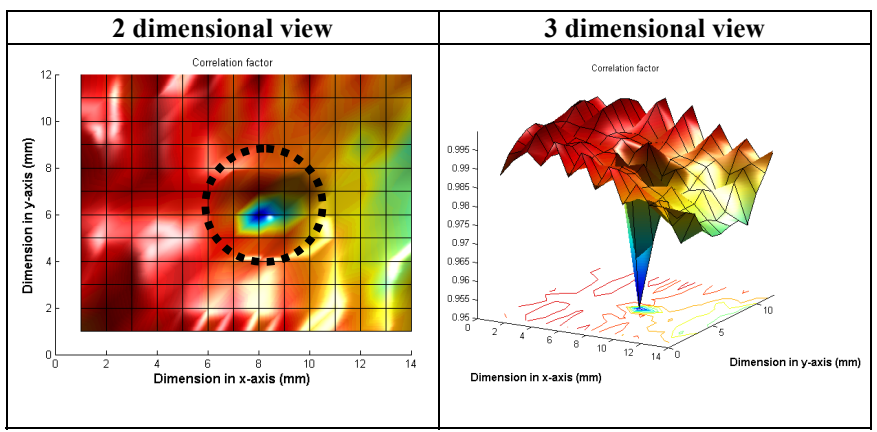

Fig. 6. Measured scanning image of $1.6 \mathrm{~mm}$ diameter hole on Inconel with stand-off distance of $1 \mathrm{~mm}$ (Defect location is highlighted in black-dashed circle)

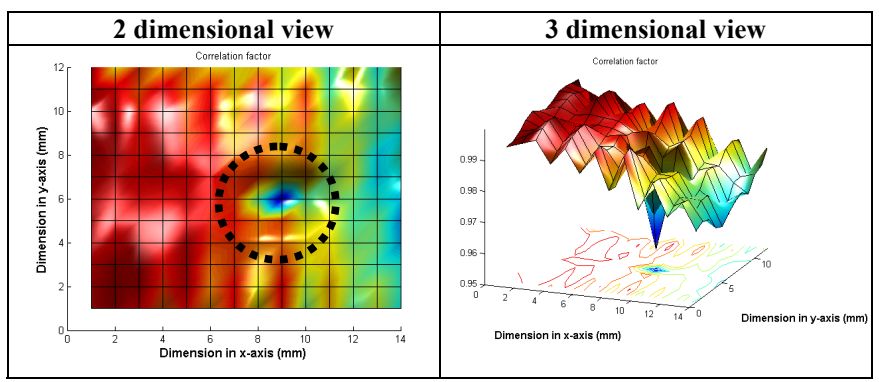

Fig. 7. Measured scanning image of $1.6 \mathrm{~mm}$ diameter hole on Inconel with stand-off distance of $2 \mathrm{~mm}$ (Defect location is highlighted in black-dashed circle)

\section{CONCLUSION}

Results have been presented for microwave NDT/E using open ended rectangular waveguide to $40 \mathrm{GHz}$. 3D electromagnetic simulation and measurement of a representative gas turbine blade material sample, with a back drilled metal defect covered by TBC, using handheld, portable microwave electronics equipment has been performed. It has been shown that correlation techniques using both magnitude and phase information of the reflection coefficient provide promising results for the use of microwave NDT/E as a complementary inspection tool for turbine component inspection, due to the defect-dependent propagation through ceramics of electromagnetic energy.

\section{ACKNOWLEDGMENT}

The first author would like to deeply thank the Public Service Department of Malaysia (JPA) and Universiti Sains Malaysia (USM) for funding his Ph.D. study at the University of Manchester, U.K. The support of Keysight Technologies is gratefully acknowledged.

\section{REFERENCES}

[1] Peter J. Shull, Nondestructive Evaluation: Theory, Techniques and Applications. New York: Marcel Dekker, 2002.

[2] R. Zoughi and S. Bakhtiari, "Microwave nondestructive detection and evaluation of disbonding and delamination in layered-dielectric slabs," IEEE Transactions on Instrumentation and Measurement, vol. 39, no. 6, pp. 1059-1063, 1990.

[3] S. Bakhtiari and R. Zoughi, "Microwave thickness measurement of lossy layered dielectric slabs using incoherent reflectivity," Research in Nondestructive Evaluation, vol. 2, pp. 157-168, 1990.

[4] S. Bakhtiari, S. I. Ganchev, and R. Zoughi, "Open-ended rectangular waveguide for nondestructive thickness measurement and variation detection of lossy dielectric slabs backed by a conducting plate," IEEE Transactions on Instrumentation and Measurement, vol. 42, no. I, pp. 19-24, 1993.

[5] M. Sayar, D. Seo, and K. Ogawa, "Non-destructive microwave detection of layer thickness in degraded thermal barrier coatings using K- and Wband frequency range," NDT and E International, vol. 42, pp. 398-403, 2009.

[6] S. Bakhtiari, N. Qaddoumi, S. I. Ganchev, and R. Zoughi, "Microwave noncontact examination of disbond and thickness variation in stratified composite media," IEEE Transactions on Microwave Theory and Techniques, vol. 42, no. 3, pp. 389-395, 1994.

[7] H. Zhang, B. Gao, G. Y. Tian, W. L. Woo, and L. Bai, "Metal defects sizing and detection under thick coating using microwave NDT," NDT and E International, vol. 60, pp. 52-61, 2013.

[8] J. Hoydis, C. Hoek, T. Wild, and S. ten Brink, "Channel measurements for large antenna arrays," in 2012 International Symposium on Wireless Communication Systems (ISWCS), 2012, pp. 811-815.

[9] F. a. Miranda, W. L. Gordon, V. O. Heinen, B. T. Ebihara, and K. B. Bhasin, "Measurements of complex permittivity of microwave substrates in the 20 to $300 \mathrm{~K}$ temperature range from 26.5 to $40.0 \mathrm{GHz}$," pp. 0-9, 1990. 